\title{
Improving Seventh Grade Students' Learning of Ratio and Proportion: The Role of Schema-Based Instruction
}

\section{Citation}

Jitendra, Asha K., Jon R. Star, Kristin Starosta, Jayne M.Leh, Sheetal Sood, Grace Caskie, Cheyenne L. Hughes, Toshi R. Mack. 2009. Improving Seventh Grade Students' Learning of Ratio and Proportion: The Role of Schema-Based Instruction. Contemporary Educational Psychology 34, no. 3: 250-264.

\section{Published Version}

doi:10.1016/j.cedpsych.2009.06.001

\section{Permanent link}

http://nrs.harvard.edu/urn-3:HUL.InstRepos:9767982

\section{Terms of Use}

This article was downloaded from Harvard University's DASH repository, and is made available under the terms and conditions applicable to Other Posted Material, as set forth at http:// nrs.harvard.edu/urn-3:HUL.InstRepos:dash.current.terms-of-use\#LAA

\section{Share Your Story}

The Harvard community has made this article openly available.

Please share how this access benefits you. Submit a story.

Accessibility 


\section{Running Head: SCHEMA-BASED INSTRUCTION}

Improving Seventh Grade Students’ Learning of Ratio and Proportion:

The Role of Schema-Based Instruction

Date Submitted: May 30, 2009 


\begin{abstract}
The present study evaluated the effectiveness of an instructional intervention (schema-based instruction, SBI) that was designed to meet the diverse needs of middle school students by addressing the research literatures from both special education and mathematics education. Specifically, SBI emphasizes the role of the mathematical structure of problems and also provides students with a heuristic to aid and self-monitor problem solving. Further, SBI addresses well-articulated problem solving strategies and supports flexible use of the strategies based on the problem situation. One hundred forty eight seventh-grade students and their teachers participated in a 10-day intervention on learning to solve ratio and proportion word problems, with classrooms randomly assigned to SBI or a control condition. Results suggested that students in SBI treatment classes outperformed students in control classes on a problem solving measure, both at posttest and on a delayed posttest administered four months later. However, the two groups' performance was comparable on a state standardized mathematics achievement test.
\end{abstract}

KEYWORDS: word problem solving, ratio and proportion, middle school students, schemabased instruction 
Improving Seventh Grade Students’ Learning of Ratio and Proportion:

The Role of Schema-Based Instruction

Reasoning with ratios and proportions requires "understanding the multiplicative relationships between rational quantities” (Boyer, Levine, \& Huttenlocher, 2008, p. 1478). This type of reasoning is widely regarded as a critical bridge between the numerical, concrete mathematics of arithmetic and the abstraction that follows in algebra and higher mathematics (e.g., Fuson \& Abrahamson, 2005; Lamon, 2007; Post, Behr, \& Lesh, 1988). Recent mathematics education policy documents echo this sentiment by identifying proportional reasoning as a "capstone” of elementary mathematics (National Research Council, 2001) and as a foundational topic for further success in mathematics (National Mathematics Advisory Panel, 2008). US students' difficulties in working with ratio and proportion are seen in both national and international assessments. On the 1996 National Assessment of Educational Progress [NAEP], only $12 \%$ of eighth grade students could successfully complete a problem that involved comparing two rates (National Research Council, 2001; Wearne \& Kouba, 2000). Similarly, on the 2003 TIMSS assessment, only 55\% of US 8th graders were able to solve a routine proportion problem. As Fujimura (2001) emphasized, "proportional reasoning requires mathematical thinking that is especially difficult for children as well as for adolescents” (p. 589) and it “transcends topical barriers in adult life” (Ahl, Moore, \& Dixon, 1992, p. 81).

One of the major difficulties noted in this domain is that students tend to use additive rather than multiplicative solution methods (e.g., "to solve 6:14 = ?:35, they find the difference between 6 and 14 and subtract it from 35 to find 27:35 rather than seek multiplicative relationships,” Fuson \& Abrahamson, 2002, p. 213). Research in this domain has examined how children reason in various proportionality tasks and the extent to which developmental or 
instructional factors influence proportional reasoning (e.g., Bright, Joyner, \& Wallis, 2003; Lamon, 1993, 2002; Lo \& Watanabe, 1997; Post et al., 1988). Proportional reasoning develops over time and "understanding at one level forms a foundation for higher levels of understanding” (Lamon, 2007, p. 637). Recommendations outlined in the research for developing children's proportional thought processes have included providing ratio and proportion tasks in a wide range of contexts (e.g., measurements, prices, rates) and ensuring that students have experienced conceptual methods before presenting symbolic methods such as cross-product algorithm for solving proportional problems (Lamon, 1999; Van de Walle, 2007).

The topics of ratio and proportion are frequently encountered in elementary and middle schools in the form of word problems. Traditionally, word problems are used to teach “mathematical modeling and applied problem solving” (Van Dooren, De Bock, Hessels, Janssens, \& Verschaffel, 2005, p. 58). That is, the word problem context provides a description of a problem-solving situation that requires responding to a question by executing "one or more operations (+, -, $\mathrm{x}, \div$ ) on the quantities in the problem” (Van Dooren et al., 2005, p. 58). However, word problem solving has proved to be a significant challenge for students, in part because it requires students to understand the language (i.e., grammatical rules of English) and factual information (e.g., 1 meter $=100$ centimeters) in the problem, identify relevant information in the problem to create an adequate mental representation, and generate, execute, and monitor a solution strategy (Desoete, Roeyers, \& De Clercq, 2003; Mayer, 1999). In short, successful word problem solving is critically dependent on students' comprehension of the relations and goals in the problem (e.g., Briars \& Larkin, 1984; Cummins, Kintsch, Reisser, \& Weimer, 1988; De Corte, Verschaffel, \& De Win, 1985; Kintsch \& Greeno, 1985; Riley, Greeno, \& Heller, 1983). Yet despite their difficulty, word problems are critical in helping children 
connect different meanings, interpretations, and relationships to the mathematical operations (Van de Walle, 2007).

There exists a rich history in the field of mathematics education of interventions designed to help students become more successful at understanding and being able to solve ratio and proportion word problems (Lesh, Post, \& Behr, 1988; Behr, Harel, Post, \& Lesh, 1992; Litwiller \& Bright, 2002; Lamon, 2007). Research on ratio and proportion word problem solving was particularly prominent in the 1980s and early 1990s (e.g., Behr, Wachsmuth, Post, \& Lesh, 1984; Harel, Behr, Post, \& Lesh, 1992; Carpenter, Fennema, \& Romberg, 1993), with scholars in mathematics education continuing to explore ways to improve students' learning of this important, yet challenging topic. Although there is evidence to support the efficacy of interventions from the mathematics education community for enhancing the mathematics performance of high and average achieving students (Cohen \& Hill, 2001; Fuson, Carroll, \& Drueck, 2000; Schoenfeld, 2002), research on how to address low achieving students' difficulties with word problem solving is somewhat conflicting. In the field of mathematics education, the approach advocated by the NCTM Standards (and that is used in most of the NSF-funded reform curricula) is a student-centered, guided discovery approach for teaching students problem solving (Mayer, 2004; NRC, 2001). However, recommendations for this kind of instructional approach are somewhat at odds with the literature on problem solving instruction for low achieving students in the field of special education, which has found that low achieving students benefit far more from direct instruction and practice at problem solving than competent problem solvers (Baker, Gersten, \& Lee, 2002; Jitendra \& Xin, 1997; National Mathematics Advisory Panel, 2008; Tuovinen \& Sweller, 1999; Xin \& Jitendra, 1999). In fact, research conducted in reformoriented classrooms suggests that many low achieving students (particularly those with learning 
disabilities) may assume passive roles and may encounter difficulties with the cognitive load of the discovery-oriented activities and curricular materials (Baxter, Woodward, \& Olson, 2001; Baxter, Woodward, Voorhies, \& Wong, 2002; Woodward, Baxter, \& Robinson, 1999). Yet, despite the robust literature from special education in support of more direct instruction for low achieving students and those with learning disabilities, many in the mathematics education community have strong negative reactions to this instructional approach, in part because of perceived associations and historical links between direct instruction and the development of rote, inflexible knowledge.

The goal of the present study was to design an instructional intervention to meet the diverse needs of students in classrooms using the research literatures from both special education and mathematics education. Our instructional intervention uses a type of direct instruction that involves explicit strategy instruction, which has strong support in the special education literature for increasing the performance of at-risk populations. However, our approach is carefully designed to address three critical concerns with the ways that direct instruction has sometimes been (mis)applied in mathematics instruction.

First, one concern about some direct instructional approaches is that the same procedure (e.g., cross-multiplication) is used to solve all problems on a page. As such, students do not have the opportunity to compare and contrast (and thus learn to discriminate) among different types of problems and approaches, perhaps leading to exclusive reliance (and perhaps rote memorization, without understanding) on a small set of problem solving strategies. Our instructional approach (described in more depth below) addresses this concern by exposing students to multiple problem types and strategies and by encouraging reflection on the similarities and differences between problems types and strategies. There is growing evidence from both the education and 
psychological literature that exposure to multiple strategies facilitates students' learning of mathematics (Gentner, Loewenstein, \& Thompson, 2003; Silver, Ghousseini, Gosen, Charalambous, \& Strawhun, 2005; Rittle-Johnson \& Star, 2007; Star \& Rittle-Johnson, 2009).

A second concern about some direct problem solving instructional approaches is the use of superficial cues such as key words (e.g., in all suggests addition, left suggests subtraction, share suggest division; Lester, Garofalo, \& Kroll, 1989) that students are encouraged to use to select an operation or a solution procedure (e.g., “cross multiply”). The use of keyword methods, focusing on surface level features, does not emphasize the meaning and structure of the problem and thus may not help students to reason and make sense of story situations to be able to successfully solve novel problems (e.g., Ben-Zeev \& Star, 2001; Van de Walle, 2007). Our approach moves away from keywords and superficial problem features and more explicitly focuses on helping students see the underlying mathematical structure of problems.

A third concern about some direct instructional approaches is the reliance on a general problem solution method that involves the use of a heuristic and multiple strategies based on George Pólya’s (1945) seminal principles for problem solving (Lopez-Real, 2006). Pólya’s (1990/1945) four-step problem solving model includes the following steps: understand the problem, devise a plan, carry out the plan, and look back and reflect. However, this method has come under scrutiny for several reasons, including the failure of general heuristics to reliably lead to improvements in students' word problem solving performance (Lesh \& Zawojewski, 2007; Schoenfeld, 1992). One plausible reason is that the strategies in the "devise a plan" step are too general to support student learning. For example, a common visual representation strategy, “draw a diagram,” may not necessarily generate a representation that emphasizes the relations between elements in the problem that is critical for successful problem solving (Hegarty 
\& Kozhevnikov, 1999). A second and related weakness of this type of approach is, as Schoenfeld (1992) argued, that the characterizations of strategies listed in Polya's heuristic are "descriptive rather than prescriptive” (p. 353). As such, these characterizations do not provide the necessary detail for individuals who are not already familiar with the strategies to implement them.

Our instructional approach, schema-based instruction (SBI), which is intermediate in generality between key word approaches and general heuristic methods described above, addresses the above-noted concerns with some aspects of direct instruction in that it entails specific problem solving strategies that are linked to particular types or classes of problems (e.g., ratio, proportion). Specifically, SBI in this study includes the following three features.

First, our instructional model uses schema training to help students see the underlying mathematical structure of word problems, which is critical to effectively deploy content knowledge. Schema theory suggests that cognizance of the role of the mathematical structure (semantic structure) of a problem is critical to successful problem solution (Sweller, Chandler, Tierney, \& Cooper, 1990). Schemas are domain or context specific knowledge structures that organize knowledge and help the learner categorize various problem types to determine the most appropriate actions needed to solve the problem (Chen, 1999; Marshall, 1995; Mayer, 1992; Sweller et al., 1990). For example, organizing problems on the basis of structural features (e.g., rate problem, compare problem) rather than surface features (e.g., the problem's cover story) can evoke the appropriate solution strategy.

One way that problem solvers can access schema knowledge is through the use of schematic diagrams that emphasize "schematic imagery (i.e., representing the spatial relationships between objects and imagining spatial transformations)” (Hegarty \& Kozhevnikov, 1999, p. 685). The use of schematic diagrams has been found to be particularly useful in 
highlighting underlying problem structure and is deemed by many to be central to mathematical problem solving (Hegarty \& Kozhevnikov, 1999; Janvier, 1987; Stylianou \& Silver, 2004; Sweller et al., 1990; Willis \& Fuson, 1988). It is important to note that a schematic diagram is not merely a pictorial representation of the problem storyline that may focus on concrete, irrelevant details, but rather depicts the relationships between critical elements of the problem structure necessary for facilitating problem solution (Hegarty \& Kozhevnikov, 1999). Research on the effectiveness of schema training in isolation or combined with schematic representations has shown that it is effective for students of different ability levels (e.g., Chen, 1999; Fuson \& Willis, 1989; Jitendra, Griffin, Haria, Leh, Adams, \& Kaduvetoor, 2007; Quilici \& Mayer, 1996; Xin, Jitendra, \& Deatline-Buchman, 2005). Further, from the cognitive load and expert/novice problem solver literatures, it appears that schema-based instruction that effectively deploys content knowledge via schematic diagrams and focuses on structural features of the problems would be most efficient for low achieving students in reducing the working memory capacity as multiple elements of information are chunked into a single schema (Kalyuga \& Sweller, 2004; Lester \& Kehle, 2003; Touvinen, \& Sweller, 1999).

A second feature of our instructional approach is our focus on multiple solution strategies. Comparing and contrasting multiple strategies is a central feature of mathematics reform efforts (Silver et al., 2005) and is advocated in the National Council of Teachers of Mathematics (NCTM) Standards (2000). An emphasis on having students actively compare, reflect on, and discuss multiple solution methods is also identified as a key feature of expert mathematics instruction (Ball, 1993; Fraivillig, Murphy, \& Fuson, 1999; Huffred-Ackles, Fuson, \& Sherin Gamoran, 2004; Lampert, 1990; Silver et al., 2005) and considered to be an important differentiating feature of teachers in countries that have performed well on international 
assessments such as the Third International Mathematics and Science Study (TIMSS) (Richland, Zur, \& Holyoak, 2007; Stigler \& Hiebert, 1999). Further, two recent studies by Rittle-Johnson and Star (2007; Star \& Rittle-Johnson, 2009) provide empirical evidence for improving student learning when instruction emphasizes and supports comparing and contrasting solutions. Students who learned to solve equations or to compute estimates by comparing and contrasting multiple solution methods outperformed students who were exposed to the same solution methods but presented sequentially. However, even though multiple strategies are perceived to have the potential for promoting mathematics learning, the literature is unclear about whether exposing low achieving students to multiple strategies will lead to successful problem solving (Woodward, 2006). Given the lack of research on the effectiveness of multiple solution strategies for learners of different ability levels, we focused on explicitly teaching a small but adequate number of strategies to scaffold the learning of low achieving students by providing well-guided instructions to reduce the cognitive overload (Kalyuga \& Sweller, 2004).

Finally, an additional feature of our instructional model is the use of "think-alouds" to help students monitor their learning and comprehension. Self-monitoring of content to be learned is a critical facet of metacognitive strategy knowledge and essential for mastering the skills of self-regulation (e.g., Pintrich, 2002; Kramarski, Mevarech, \& Arami, 2002; Kramarski \& Mizrachi, 2006). As Coldberg and Bush (2003) noted, "Mathematical strategy knowledge naturally includes knowledge of algorithms and heuristics, but it also includes a person's awareness of strategies to aid comprehending problem statements, organizing information or data, planning solution attempts, executing plans, and checking results" (p. 168). In SBI, teachers model how and when to use each problem solving strategy (Roehler \& Cantlon, 1997) and work with students to reflect on the problem before solving it. Recent research suggests that 
instruction that includes a focus on metacognitive strategy knowledge also has a positive effect on students' mathematical problem solving performance (Fuchs et al., 2003; Kramarski, Mevarech, \& Arami, 2002; Verschaffel, De Corte, Lasure, Van Vaerenbergh, Bogaerts, \& Ratinckx, 1999). Evidently, problem-solving instruction that addresses metacognitive strategy knowledge serves to promote transferable knowledge (De Corte, Verschaffel, \& Masui, 2004; De Corte, Verschaffel, \& Op’t Eynde, 2000; Harris, Graham, \& Mason, 2006; Shunk \& Zimmerman, 1994; Zimmerman, 1989, 2008). SBI's emphasis on metacognitive strategy knowledge involves having students monitor their cognitive thought processes (i.e., problem solving behavior) to focus on comprehending the problem, representing the problem, planning to solve the problem using appropriate strategies, and reflecting on the solution via the use of "think-alouds.” The goal of metacognitive strategy knowledge training was to facilitate students' thinking about the problem solving process. Based on the work of Zimmerman and others (e.g., Harris, Graham, \& Mason, 2006; Pintrich, 1990; Zimmerman \& Martinez-Pons, 1990), we hypothesized that metacognitive strategy knowledge training can help increase the performance of all students, including low achieving students. However, low achieving students may require more practice, time, and scaffolding compared to students at other achievement levels to monitor and control their learning processes.

\section{Prior Evidence in Support of Schema Training}

There is growing evidence regarding the benefits of explicit schema training using visual representations on students' learning of mathematics (Fuchs, Seethaler, Powell, Fuchs, Hamlett, Fletcher, 2008; Fuson \& Willis, 1989; Griffin \& Jitendra, 2008; Jitendra, DiPipi, \& PerronJones, 2001; Jitendra, Griffin, Deatline-Buchman, \& Sczesniak, 2007; Jitendra et al., 2007; Jitendra, Griffin, McGoey, Gardill, Bhat, \& Riley, 1998; Jitendra \& Hoff, 1993; Jitendra, Hoff, 
\& Beck, 1999; Lewis, 1989; Willis \& Fuson, 1988; Xin et al., 2005; Zawaiza \& Gerber, 1993). For example, Fuchs et al. (2008) used a randomized controlled study to test the efficacy of schema training on the math problem solving performance of third grade students with math and reading difficulties, whose average mathematics performance was at about the $10^{\text {th }}$ percentile on a standardized arithmetic test. The intervention, delivered by trained research assistants, was taught for 30 minutes per session, three days per week, for 12 weeks. The intervention not only focused on the mathematical structure of three types of addition/subtraction word problem types, it also emphasized "transfer solution methods to problems that include irrelevant information, 2digit operands, missing information in the first or second position in the algebraic equation, or relevant information in charts, graphs, and pictures” (p. 155). Results indicated that students in the schema training group made significant gains when compared to the control group on the researcher-designed problem solving measure $(\mathrm{ES}=1.80)$. Although results were not statistically significant on the commercial tests of word problems, a significant effect was found on a standardized arithmetic test $(\mathrm{ES}=1.34)$.

The present work is based on several similar studies by Jitendra and colleagues. In a recent randomized controlled study, Jitendra et al. (2007) explored the effectiveness of SBI on problem solving and computation skills in the domain of addition and subtraction word problem solving. Participants included a sample of mostly low achieving students (i.e., 73\% of the students scored at or below the $34^{\text {th }}$ percentile on a standardized mathematics problem solving test.), who received the intervention for 25 minutes daily, five days per week, for about 13 weeks. Students in the control condition learned to solve problems using a variant of Polya's four-step heuristic, which included four problem-solving strategies (i.e., using objects, acting it out or drawing a diagram, choosing an operation/writing a number sentence, using data from a 
graph or table) found in mathematics textbooks. Results revealed that SBI was more effective than the control condition at enhancing students' mathematical word problem solving skills. The effect sizes (ES) comparing the SBI group with the comparison group were 0.52 at posttest and 0.69 at maintenance. Further, the SBI groups' performance exceeded that of the comparison group on the state assessment of mathematics performance $(\mathrm{ES}=0.65)$. On the computation test, both groups made gains over time (six weeks later).

As another example, Jitendra et al. (2002) extended this work on schema-based instruction to the domain of multiplication and division word problem solving, in a small study with four students with learning disabilities in $8^{\text {th }}$ grade using a single subject design methodology. All four participants scored at least $1 \mathrm{SD}$ or more below the mean on a standardized mathematics achievement test. The intervention occurred for 35-40 min per session for a total of about 18 sessions (range $=16$ to 20 sessions). Results revealed strong positive effects on acquisition and maintenance (i.e., 2.5 weeks to 10 weeks following the termination of instruction). In addition, transfer to novel and more complex problems (i.e., multistep) occurred for all four students.

More recently, Xin et al. (2005) conducted a study of students' learning of ratio and proportion word problem solving. Participants included students with learning problems, who scored at least $1 \mathrm{SD}$ or more below the mean on a standardized mathematics achievement test. The intervention occurred three to four times a week, about one hour per session, for a total of 12 sessions. Results showed that students receiving schema-based instruction significantly outperformed a comparison group receiving direct instruction on Polya's four-step problemsolving procedure on an immediate posttest $(\mathrm{ES}=1.69)$, delayed posttests $(\mathrm{ES}>2.50)$, and a transfer test $(\mathrm{ES}=0.89)$ that included items from standardized mathematics achievement tests. 


\section{Purposes of the Present Study}

The primary purpose of the current study was to further evaluate the effectiveness of schema based instruction on ratio and proportion word problem solving. The present study extended the work of Jitendra and colleagues (e.g., Xin et al., 2005) on SBI in the multiplicative domain in several ways. First, while Xin et al. exclusively focused on students with disabilities and low achieving students, we targeted students of diverse ability levels in general education classrooms. Second, we extended the focus of Xin et al. beyond ratio and proportion word problem solving to also include foundational concepts (ratios, equivalent fractions, rates, fraction and percents) involved in ratio and proportion problem solving. Third, in addition to the schematic diagrams for organizing information (as was used in Xin et al.), we also incorporated multiple solution strategies and flexible application of those strategies. Fourth, instruction was provided by classroom teachers, rather than by research assistants (as was done in Xin et al.). Finally, although our measure of problem solving is researcher-designed as in the Xin et al. study, items were used verbatim from $8^{\text {th }}$ grade national and state assessments and were used to assess both word problem solving as well as ratio and proportion concepts.

A second purpose of the study was to assess maintenance of the strategy effects over time. Unlike the Xin et al. (2005) study that assessed maintenance effects one week to three months later, this study assessed maintenance of skills four months following the termination of the intervention. A third aim of the present work was to use a standardized state mathematics test to assess the generalization effects of SBI (as was done in Jitendra et al., 2007).

We hypothesized that students receiving SBI instruction would make greater gains in problem solving performance than their peers receiving "business-as-usual” mathematics instruction (control condition). The following research questions were addressed in this study: 
(1) What is the influence of SBI compared to the control treatment on the acquisition of seventh grade students' ratio and proportion word problem solving ability? (2) To what extent do SBI and control treatments impact the maintenance of problem solving performance four months following the end of intervention?; and (3) Do the treatments differentially influence transfer to performance on state wide mathematics assessment?

\section{Method}

\section{Participants}

Seventh grade students from eight classrooms and their teachers in a public, urban school participated in the study. For mathematics instruction, students in the school were grouped into same ability classes on the basis of their grades in mathematics from the previous school year (e.g., sixth grade). The school's classrooms represented four different ability levels: Honors (advanced), Academic (high), Applied (average), and Essential (low). Note that students in the Honors classrooms were not included in the study, because these students were learning advanced content (e.g., $8^{\text {th }}$ grade). In the present study, each treatment group (SBI and control) included two sections of average and one each of high and low ability classrooms to adequately represent the different levels in the school. In addition, performance on the Mathematical Problem Solving subtest of the Stanford Achievement Test-10 (SAT-10 MPS; Harcourt Brace \& Company, 2003) administered at the beginning of the school year supported the ability level categories in that the mean problem solving scaled scores of high, average, and low ability levels were $675.52(S D=22.56), 646.00(S D=25.41)$, and $618.52(S D=17.70)$, respectively. The sample of 148 students (79 girls, 69 boys) included those who were present for both the pretest and posttest. 
The mean chronological age of students was 153.12 months (range $=137.04$ to 174.96; SD $=5.76)$. The sample was primarily Caucasian $(54 \%)$, and minority students comprised $22 \%$ Hispanic, 22\% African American, and 3\% American Indian and Asian. Approximately 42\% of students received free or subsidized lunch and 3\% were English language learners. Of the 15 (10\%) special education students in the sample, 14 had an individualized education plan (IEP) in both mathematics and reading, whereas one student had an IEP in reading only. Further, five students (3\%) in the study were English language learners (ELL).

Table 1 provides student demographic data by condition for each ability level status. A one-way analysis of variance (ANOVA) indicated that the difference between the two groups, $F$ $(1,146)=0.36, p=0.55$, on age was not statistically significant. Chi-square analyses revealed no statistically significant between-group differences on gender, $X^{2}(1)=0.04, p=0.83$; ethnicity (i.e., white or non-white), $X^{2}(2)=0.51, p=048$; free or subsidized lunch, $X^{2}(1)=0.12, p=$ 0.91 , and special education status, $X^{2}(1)=2.75, p=0.10$. The 148 children in the complete data set were demographically comparable to students who were absent on one or more days on which the pretest or posttest were administered.

All six teachers at the participating school were responsible for teaching mathematics in the different ability level classrooms. For the purpose of this study, two teachers each served as intervention or control teachers only. To control for teacher effects, the other two teachers served as both intervention and control teachers and taught students in the average ability classrooms. The teachers (3 females and 3 males) were all Caucasian, with a mean of 8.58 years of experience teaching mathematics (range 2 to 28 years). Three of the teachers held secondary education certification, four had a master's degree, and only three had a degree in mathematics. In these classrooms, the teachers used the Glencoe Mathematics: Applications and Concepts, 
Course 2 textbook (Bailey et al., 2004) published by McGraw-Hill. In previous lessons, the teachers had covered integers and algebra, data analysis, and geometry.

\section{Design}

A pretest-intervention-posttest-retention test design was used. After matching classrooms in pairs on the basis of ability level, one classroom from each pair was randomly assigned to the SBI or control treatment.

\section{Intervention Materials}

The SBI intervention unit content provided the basis for solving problems involving ratios and proportions (see scope and sequence in Table 2). We identified specific concepts and problem-solving skills by reviewing the textbook used in the $7^{\text {th }}$ grade classrooms and appropriately mapping the relevant topics to the ratio and proportion unit. The unit included exercises to build an understanding of the concepts of ratios and rates that are critical to understanding proportions and for engaging in proportional reasoning as well as to solving ratio and proportion word problems.

Lessons 1 and 2 focused on the meaning of ratios, equivalent ratios, and comparison of ratios. Activities emphasized ratios in different contexts and included selecting an equivalent ratio and comparing ratios to identify ratios that are equivalent. Lessons 3 and 4 focused on expressing ratios in different ways (e.g., a:b; a is to b; a to b; a per b); part-to-part ratios as one part of a whole to another part of the same whole (e.g., the ratio of girls to boys in the class); and part-to-whole ratios as comparisons of a part to a whole (e.g., the ratio of girls to all students in the class). Further, these lessons targeted solving ratio word problems that included the use of schematic diagrams and different solution strategies. Lesson 5 extended the understanding of ratios to the topic of rates, which involve comparison of two quantities with different units (e.g., 
inches to yards, miles to gallons, computers to students). Lessons 6 and 7 involved the application of rates in different contexts to solve proportion word problems. Lessons 8 and 9 introduced scale drawings and scale models and required solving scale drawing problems (proportion). Lesson 10 examined the special way that fractions and percents are related. (Each lesson in the unit included homework problems to review the content presented in the lessons. Examples of items included in the materials were based on items derived from several published curricula.)

Procedure

Both conditions. Students in both conditions received instruction on ratio and proportion and were introduced to the same topics (i.e., ratios, rates, solving proportions, scale drawings, fractions, decimals, and percents) during the regularly scheduled mathematics instructional period for 40 minutes daily, five days per week, across 10 school days, delivered by their classroom teachers in their intact math classes. Lessons in both intervention and control classrooms were structured as follows: (a) students working individually to complete a review problem followed by the teacher reviewing it in a whole class format, (b) the teacher introducing the key concepts/skills using a series of examples, and then (c) assigning homework. Further, students in both conditions were allowed to use calculators.

SBI. For the SBI condition, the researcher-designed unit replaced the students' regular instruction on ratios and proportions. Lessons were scripted to provide a detailed teaching procedure (i.e., questions to ask, examples to present) for the purpose of ensuring consistency in implementing the critical content. However, rather than read the scripts verbatim, teachers were encouraged to be familiar with them and use their own explanations and elaborations to implement SBI. 
To solve ratio and proportion problems, students were taught to identify the problem schema (ratio or proportion) and represent the features of the problem situation using schematic diagrams (see Figure 2 for sample ratio diagram). Students first learned to interpret and elaborate on the main features of the problem situation. Next, they mapped the details of the problem onto the schema diagram. Finally, they solved ratio and proportion problems by applying an appropriate solution strategy (e.g., unit rate, equivalent fraction, or cross multiplication). A fourstep strategy (FOPS; F - Find the problem type, O - Organize the information in the problem using the diagram, $\mathrm{P}$ - Plan to solve the problem, S - Solve the problem) was developed to help anchor students' learning. A checklist was used to introduce and discuss the FOPS strategy to solve ratio and proportion word problems. Using the checklist that contained the strategy steps and self-instructions, the teacher modeled the use of the strategy while "thinking aloud." For example, using Step 1 of the strategy, the teacher identifies the problem type by reading, retelling, and examining information (e.g., compared, base, and ratio value) in the problem (ratio) to recognize it as a ratio or proportion problem via self-instructions (e.g., Is there a ratio statement that tells about a multiplicative relationship between two quantities?). In addition, the teacher makes the connection between previously solved problems and the new problem. For Step 2, the teacher demonstrates how to organize information using the schematic diagram (e.g., ratio). This step includes self-instructions to read the problem to identify critical information in the problem to represent using the schematic diagram. In Step 3 of the plan, students learn to translate the information in the diagram into a math equation. Further, the teacher directly teaches a variety of solution methods (cross multiplication, equivalent fractions, unit rate strategies) to solve the word problems. During the plan step, students learn to discriminate between instances when a particular solution strategy is appropriate based on the numbers in the 
problem. Finally, Step 4 has the students solve the problem using the solution strategy identified in Step 3, justify the derived solutions using the schema features as anchors for explanations and elaborations, and check the accuracy of not only the computation but also the representation.

In sum, the instructional approach encouraged students' "think-alouds" to monitor and direct their problem-solving behavior along the following dimensions: (a) problem comprehension (e.g., Did I read and retell the problem to understand what is given and what must be solved?, Why is this a ratio problem?, How is this problem similar to or different from one I already solved?), (b) problem representation (e.g., What schematic diagram can help me adequately represent information in the problem to show the relation between quantities?), (c) planning (e.g., How can I set up the math equation? What solution strategy can I use to solve this problem?), and (d) problem solution (e.g., Does the answer make sense? How can I verify the solution?)

Although each lesson included teacher-mediated instruction followed by guided learning and independent practice in using schematic diagrams and metacognitive strategy knowledge checklists, instructional support with regard to the use of schematic diagrams in SBI was gradually faded within and across lessons. For example, instruction ultimately involved condensed versions of the original schematic diagrams; however, the connections to the underlying problem structure in the schematic diagrams were always present, to ensure that students continued to effectively represent the information in the problem.

Control. Students in the control group received instruction from their teachers who used procedures outlined in the district-adopted mathematics textbook (Bailey et al., 2004). Each lesson in the chapter on Ratios and Proportions begins with a real-life application of the mathematics to introduce and motivate the day's topic. The text then suggests a direct instruction 
approach for defining key concepts (e.g., “A proportion is an equation stating that two ratios are equivalent,” Bailey et al., 2004, p. 297). Subsequently, several worked out examples are presented to expose students to the target problem types of the lesson, following by a period of guided practice.

\section{Measures and Data Collection}

Classroom teachers administered the mathematical word problem solving tests and the student metacognitive strategy knowledge assessment using scripted directions and research assistants, who observed teachers' adherence to standardized administration protocols, scored them using answer keys. In addition, classroom teachers administered the Pennsylvania System of School Assessment (PSSA; Pennsylvania State Department of Education, 2000) mathematics test as part of the statewide evaluation program. All data were collected in a whole-class arrangement.

Mathematical problem-solving (PS) test. To assess mathematics competence on ratio and proportion problems, students completed a researcher-designed mathematical PS test prior to instruction (pretest), immediately following instruction (posttest), and four months following instruction (delayed posttest). The PS test consisted of 18 items derived from the $8^{\text {th }}$ grade TIMSS, NAEP, and state assessments and assessed ratio and proportion concepts and word problem solving knowledge similar to the instructed content (see sample item in Figure 1). Students had 40 minutes to complete the same 18-item test at pretest, posttest, and delayed posttest. Directions for administering the problem-solving test required students to show their complete work. Scoring involved assigning one point for the correct answer and no points for an incorrect answer. On this sample, Cronbach’s alpha was 0.73 for the pretest, 0.78 for the posttest, and 0.83 for the delayed posttest. Interscorer agreement assessed by two research assistants 
independently scoring $100 \%$ of the protocols was .96 at pretest, .97 at posttest, and .99 at delayed posttest.

Mathematics Subtest of the Pennsylvania System of School Assessment (PSSA). Students completed the PSSA mathematics test at the end of Grade 7, which served as a generalization measure. The PSSA mathematics test is a group administered, standards-based criterionreferenced assessment used to measure a student's attainment of the academic standards (e.g., number systems and relationships, mathematics reasoning and connections, measurement and estimation, geometry, algebra, statistics and data analysis). It includes both multiple choice and open-ended items. According to the PSSA technical manual, Cronbach's alphas are greater than .90 for the PSSA mathematics test. Concurrent validity coefficients with CTBS/TerraNova (CTB/McGraw Hill, 2001) and California Achievement Test (Version 5; CTB/McGraw-Hill, 1986) are around .80 and predictive validity with Stanford Achievement Test (SAT) is about .90.

Student Metacognitive Strategy Knowledge Assessment. We assessed students' metacognitive strategy knowledge using a modified version of a questionnaire developed by Fuchs et al. (2003) with four statements that related to the FOPS problem solving steps used in SBI. The four statements were as follows: "When I work on a math story problem, I think about what kind of problem it is," "When I come to a new kind of math problem, I know how to see if it is similar to a problem that I have seen before," "I know how to organize information from a word problem using a diagram," and "I know how to check if my answer makes sense when solving word problems." Each response was coded as true $=2$, kind of true $=1$, and not true $=0$.

In addition, students were provided a list of the FOPS problem-solving steps and asked to check all steps that they knew how to do well. Each response received a score indicating students' perceptions of whether they knew the steps or strategy well (1 point) or not (0 points). 
A total score (out of 4 possible points) was calculated to indicate students' familiarity with FOPS as a whole. Similarly, students were provided a list of the three solution strategies included in the ratio and proportion unit and asked to check which strategies they felt they were able to "easily use to solve ratio and proportion word problems." Each response received a score indicating students' perception that they could use the strategy easily (1 point) or not ( 0 points). A total score (out of 3 possible points) was calculated to indicate students' perceived knowledge of the three strategies as a whole. Cronbach's alpha was 0.65 for the metacognitive strategy knowledge assessment. Interscorer agreement assessed by two research assistants independently scoring $100 \%$ of the protocols was .98 .

Treatment implementation fidelity. Checklists of important features of instruction (e.g., reviews homework/sets the purpose for the lesson, leads a discussion of key concepts, models solving the problem by applying the problem-solving strategy, has students generate problems and discuss solving them) in the scripts for each lesson were developed for the SBI treatment to assess fidelity of treatment. Research assistants observed all 10 lessons across the four treatment teachers, which were also videotaped. A research assistant checked the steps of the lesson feature checklist as they were completed to compute the percentage of important lesson features that were implemented. In addition, a second rater either observed the lesson or viewed the videotaped lesson and independently computed the percentage of lesson features implemented to determine interrater reliability. In addition to completing fidelity checklists, observers in SBI classrooms also took detailed field notes about teacher and student interactions, instructional grouping, and classroom climate. We also observed and took detailed field notes in control classrooms (48\% of lessons across the four control teachers). 


\section{Professional Development}

Teachers assigned to the SBI condition attended a 1-day session that described the goals of the study and how to mediate instruction and facilitate discussions and group activities. The professional development materials included: (a) presenting a proportion problem from the TIMSS assessment and engaging teachers in a discussion of how their students would approach these problem types as well as analyzing student solutions, explanations, and difficulties; (b) demonstrating the underlying structure of ratio and proportion problem types by using schematic diagrams to organize the information in the problem to highlight the essential features, (c) discussing how to introduce the procedures inherent to the SBI approach and eliciting student discussions, and (d) having teachers read the lesson plans and focusing discussion on how to represent problems using schematic diagrams, explain common rules and procedures, self monitor strategy usage, and analyze students’ solutions and explanations. In addition, ongoing technical assistance was available to the SBI teachers throughout the duration of the study. Project team members met with each teacher individually as needed to address individual concerns.

Teachers in the control condition attended one half-day training session that also included presenting a proportion problem from the TIMSS assessment and engaging teachers in a discussion of how their students would approach these problem types as well as analyzing student solutions, explanations, and difficulties. Further, the training focused on the goals of the study and the importance of implementing the standard "business-as-usual" curriculum faithfully. 


\section{Data Analysis}

The unit of analysis for the mathematics measures was each student's individual score. Even though classrooms were nested in instructional treatments, and students were nested in classrooms and treatments, we did not use classroom as the unit of analysis due to limited number of classrooms. Treatment group and ability level were fixed factors. The mathematics problem solving data were first examined for initial group comparability on the problem solving pretest measure by contrasting the SBI with the control treatment, using a 2 group (SBI, control) x 3 ability level (high, average, low) analysis of variance (ANOVA). Next, we assessed the acquisition and maintenance effects of the problem solving skill by conducting separate twofactor analysis of covariance (ANCOVA) with the problem solving pretest serving as a covariate for both the posttest and delayed posttest. ANCOVA was selected to reduce the probability of a Type II error and to increase power by reducing the error variance (StatSoft, 1998). To assess generalizations effects, we carried out a two-factor analysis of variance (ANOVA) on the PSSA mathematics test scaled scores. Treatment group and ability level served as the between-subjects fixed factors. To assess metacognitive strategy knowledge in the SBI condition, we conducted a multivariate analysis of variance (MANOVA) on items on the student metacognitive strategy knowledge questionnaire. Ability level served as the between-subjects fixed factor.

To estimate the practical significance of effects, we computed posttest effect sizes (Cohen's $d$ ) for the problem-solving test by dividing the difference between the regressed adjusted means (i.e., adjusted for the pretest covariate) by the square root of the mean square error (Glass, McGaw, \& Smith, 1981). Effects sizes were deemed to be small (.20), medium (.50), or large (.80) based on Cohen's interpretation. Further, we provide descriptive statistics for the treatment fidelity data. 


\section{Results}

\section{Student Learning}

Table 3 presents the mean scores, adjusted mean scores, and standard deviations on mathematical problem solving and PSSA mathematics scores by condition and ability level status. Table 4 provides the mean scores and standard deviations on the student metacognitive strategy knowledge questionnaire by ability level for the SBI group.

\section{Pretreatment Comparability}

The ANOVA applied to the pretest scores indicated no statistically significant main effect for group, $F(1,142)=1.10, p=.30$, indicating group equivalency before the beginning of the study. However, there was a statistically significant main effect for ability level, $F(2,142)=$ 27.69, $p<.001$. Post-hoc analyses using the Bonferroni post hoc criterion for significance indicated that the mean problem solving scores for the ability levels were significantly different (High $>$ Average $>$ Low). No significant interaction between group and ability level was found, $F(2,142)=0.26, p=.77$

\section{Differential Word Problem Solving Learning as a Function of Treatment}

Results of the ANCOVA applied to the posttest scores demonstrated statistically significant main effects for group, $F(1,141)=6.30, p=.01$, and ability level, $F(2,141)=$ 16.53, $p<.001$ (see Table 3). The pretest was found to be a significant covariate, $F(1,142)=$ 32.16, $p<.001$. The adjusted mean scores indicated that the SBI group significantly outperformed the control group. A low medium effect size of .45 was found for SBI when compared with control. Post-hoc analyses using the Bonferroni post hoc criterion for significance indicated that the mean problem solving scores for the ability levels were significantly different 
(High > Average $>$ Low). No significant interaction between group and ability level was found, $F(2,141)=2.01, p=0.14$

In addition, results from the delayed posttest administered four months following the completion of the intervention indicated statistically significant effects for group, $F(1,135)=$ 8.99, $p<.01$, and ability level, $F(2,135)=24.16, p<.001$ (see Table 3 ). The pretest was found to be a significant covariate, $F(1,135)=34.06, p<.001$. The adjusted mean scores indicated that the SBI group significantly outperformed the control group. A medium effect size of .56 was found for SBI when compared with control. Post-hoc analyses using the Bonferroni post hoc criterion for significance indicated that the mean problem solving scores for the ability levels were significantly different (High > Average $>$ Low). No significant interaction between group and ability level was found, $F(2,135)=2.04, p=0.13$.

Posttreatment Performance on the PSSA Mathematics Test as a Function of Treatment

On the PSSA posttest scores, there was no statistically significant effect for group, $F$ (1, $132)=0.35, p=.56$. However, a statistically significant effect for ability level, $F(2,132)=$ 97.33, $p<.001$, was found. Post-hoc analyses using the Bonferroni post hoc criterion for significance indicated that the mean PSSA scores for the ability levels were significantly different (High > Average > Low). No significant interaction between group and ability level was found, $F(2,132)=1.512, p=0.22$.

Student Metacognitive Strategy Knowledge Assessment

Results did not indicate a significant ability level effect on the metacognitive strategy knowledge assessment related to the FOPS steps. However, on the four statements relating to the FOPS on the questionnaire, low ability students' responses to the item about "I know how to organize information from a word problem using a diagram” suggested that they were not 
completely sure (0.83) about organizing information, as compared to average (1.29) and high ability students (1.32); see Table 4. Similarly, on the questions assessing students' perception of which FOPS steps they knew how to do well, the mean score for the four FOPS steps (out of 4 possible points; see Table 4) indicated moderate levels of ease with applying FOPS (high = 2.68; average $=2.14$; low $=2.33$ ). When considering each step of FOPS, however, student responses indicated that the Solve step was one that they knew how to do well (high $=0.95$; average $=0.89$; low $=0.83$, while responses to the remaining three steps ranged from 0.34 to 0.64 , indicating low to moderate levels of ease in applying them, for students of all ability levels. Finally, with regard to the perceived ease of the three solution strategies for solving ratio and proportion word problems, inspection of means indicates that high ability students perceived all three strategies to be equally easy to apply (mean for cross multiplication $=0.68$, equivalent fractions $=0.68$, unit rate $=0.64)$. In contrast, both average and low ability students deemed cross multiplication to be relatively easier (0.83 and 0.75 , respectively) than equivalent fractions ( 0.63 and 0.33 , respectively) or unit rate strategies ( 0.51 and 0.50 , respectively).

\section{Treatment Fidelity and Description of Instruction}

Recall that six teachers participated in the study; four taught treatment sections and four taught control sections (two teachers taught both treatment and control sections). Across the classroom observations in the SBI classrooms, mean treatment fidelity for the four teachers was $80 \%$ (range $=60 \%$ to $99 \%$ ), indicating moderate levels of implementation. Interrater agreement of treatment fidelity was $90 \%$ (range $=67 \%$ to $100 \%$ ).

More qualitatively, our observations of treatment teachers' classrooms indicated that they appeared comfortable using the scripted lessons, in that they adhered to the script without having to read it verbatim. In the initial lessons, one teacher experienced challenges with coordination of 
materials (i.e., keeping track of the overhead sheets of the lesson's problems); however, as the lessons progressed, this concern faded. Teachers made minor adjustments to the flow and pace of the lessons based on their perceptions of students' comprehension of the material. For example, when students consistently responded to questions with correct answers, teachers skipped the more repetitive, review questions in order to keep the lesson moving. At other times, teachers identified topics or specific problems that required additional instruction and provided elaboration and review as needed. Additionally, one of the teachers often personalized the content to increase student engagement, such as providing personal anecdotes to situate the word problems in everyday contexts.

One of the four treatment teachers, who taught a low ability class, consistently had difficulty completing a day’s lesson in a single class period, for a number of reasons. First, and especially at the start of the unit, this teacher was challenged by teaching from a script and thus was not particularly efficient in his instruction. Second, the low achieving students in this teacher's class often needed extra time to comprehend the day's material. Finally, this teacher had difficulty maintaining control over his classroom; off-task and noncompliant behaviors at times interfered with and decreased the rate of instruction.

A component of the intervention that was challenging for all treatment teachers was the use of the FOPS self-monitoring checklist. In the first lesson in which the checklist appeared, the teachers referred to it and completed the steps. However, as the unit progressed, teachers decreased their use of this checklist, in part because of their perception that the students did not need it. Researcher-observers encouraged the use of the checklist and provided materials to facilitate its use (e.g., re-positional paper flags to keep track of the steps of the checklist; large laminated printout of the checklist to be posted on the wall); these efforts were only moderately 
successful. Teachers used the latter three steps (“Organize the information,” "Plan to solve,” and "Solve”) most frequently, but the first step ("Find the problem type”), as well as its subordinate steps (e.g., "How is this problem like a problem I've solved before?," "How do I know this is a ratio problem?”) were infrequently discussed in detail.

Another feature of treatment classroom instruction that merits mention is the variation in how teachers went over homework. Two teachers progressed through each day's homework quickly (e.g., providing students with the answers on an overhead, only going over problems that appeared to be most confusing to the students). However, the other two treatment teachers frequently dedicated nearly half of the class period to reviewing homework, leaving little time for the actual lesson. These were also the same teachers who taught the control classes and felt equally comfortable adhering to the assigned instruction in both curricula. As such, we did not perceive any issues related to the demands of switching between conditions.

In control classrooms, there was a high degree of uniformity in the structure of teachers' lessons. All four teachers began the class by reviewing homework, typically by solving problems on the board. The day's new material was then introduced, followed by opportunities for students to independently practice using the day's new skills (often with the teacher circulating around the room). Toward the end of the class, students were typically given time to begin working on their homework.

Control teachers varied, however, in their instruction of problem-solving strategies. Recall that a key feature of SBI is its focus on multiple strategies for approaching ratio and proportion problems, including cross-multiplication, unit rate, and equivalent fractions; students’ regular mathematics textbook relied exclusively on cross-multiplication. Two control teachers of average ability classes, who also taught in the treatment classes, adhered to the text and only 
focused on cross-multiplication. However, control teachers of high and low ability classes introduced multiple strategies. In the low ability class, the teacher discussed both the equivalent fractions and cross-multiplication strategies, but he instructed students to use only cross multiplication because it always works. In the high ability class, the teacher introduced all three strategies for solving ratio and proportion problems and instructed students to choose the strategy that was most appropriate for a given problem.

\section{Discussion}

This study replicates and extends prior work by Jitendra and colleagues and others on the effects of schema-based instruction on students' learning of mathematics. The focus here was on ratio and proportion, a critically important but quite challenging content area for students. Our SBI approach is relatively unique in its synthesis of best practices from the at-times conflicting special education and mathematics education literatures. SBI uses explicit strategy instruction, which has been shown by special education researchers to be effective with low achievers, but with an emphasis on multiple strategies and the underlying mathematical structure of word problems - two features with strong foundation in the mathematics education and cognitive science research literatures.

The first and second research questions addressed the differential effects of SBI and control treatment on the acquisition and maintenance of seventh grade students' ratio and proportion word problem solving performance. Consistent with our prediction, we found a statistically significant difference in students’ problem-solving skills favoring the SBI condition, suggesting that SBI represents one promising approach to teaching ratio and proportion word problem solving skills. In addition, our results indicated that the benefits of SBI persisted four months after the intervention. The effect sizes comparing the SBI treatment with the control 
group were 0.45 on the immediate posttest and 0.56 on the delayed posttest. It is important to note that our control group received instruction on the same topics and for the same duration of time as the SBI group. At the same time, the effects for SBI were not mediated by ability level, suggesting that it may benefit a wide range of seventh grade students. In sum, our use of direct instruction, but modified to move students beyond rote memorization to developing deeper understanding of the mathematical problem structure and fostering flexible solution strategies, enhanced the problem solving performance of students in the SBI group and promoted maintenance of the problem-solving skill over time.

The third research question addressed differences in the potential of the SBI treatment for improving performance on statewide mathematics assessment. Contrary to our hypotheses, the SBI treatment did not show an advantage over the control treatment on the statewide mathematics test. One plausible explanation for this finding is that the 10-day intervention was not sufficient for students in the SBI group to adequately transfer what they learned about problem solving and mathematical structure in ratio and proportion problems to the many other problem types present on the PSSA. This finding further highlights the importance of adequate time for the development of schemata or conceptual learning, because students were not able to abstract the key elements that underlie specific classes of problems learned to apply to novel problems. In contrast to the posttest that was aligned more closely with the content domain, the statewide mathematics achievement test included broad categories of problem types that posed a greater degree of novelty than the posttest and would be deemed to be a far transfer test. Consequently, this far transfer test would require increasing levels of metacognitive strategy knowledge for students to apply their schematic knowledge to solve the novel problems. Future research should seek to address this issue, both by investigating the impact of longer 
interventions and also by modifying SBI in an attempt to help students make connections to content outside of the instructional domain.

The present findings are consistent with our hypothesis that schema training with visual representations benefits students of diverse ability levels. These results build upon the success of previous studies on SBI (e.g., Fuchs et al., 2008; Jitendra et al., 1998, 2007; Xin et al., 2005) in several important ways. First, acquisition effects for the SBI treatment in the present study are positive, with effect sizes that are either similar (Jitendra et al., 1998, 2007) or smaller (Fuchs et al., 2008; Xin et al., 1995) than effect sizes found in prior work. Similarly, maintenance effects are either similar (Jitendra et al., 1998, 2007) or smaller (Xin et al., 1995) than effect sizes found in prior work. The moderate effect size for acquisition in our study is promising when considering the short-term (2-week) intervention as compared to similar interventions that typically lasted about 12 weeks in duration. It is also worth noting that classroom teachers rather than researchers (Fuchs et al., 2008, Xin et al., 2005) provided the instruction in the present study. Research indicates that researcher implemented treatments are generally associated with greater effects than teacher implemented treatments (Swanson, Hoskyn, \& Lee, 1999).

Of special interest in our study was the finding that the effect size for the delayed posttest was larger than what was found at posttest, which supports prior findings of Jitendra and colleagues (Jitendra et al., 1998, 2007; Xin et al., 2005). This finding is encouraging given that an important test of the effectiveness of an intervention is information about the "delayed or long-term effects” of the intervention (Gersten, Fuchs, Compton, Coyne, Greenwood, \& Innocenti, 2005, p. 159); the delay used in this study (of four months) was longer than in prior SBI studies. Based on visual examination of the data, both average and high ability students in 
SBI scored higher on the delayed posttest than students in the control condition 4 months after the intervention ${ }^{1}$.

At the same time, it is difficult to sort out which aspect(s) of our intervention package (e.g., use of schematic diagrams, focus on metacogntive strategy knowledge) may have contributed to the success of our intervention. One of the critical features of SBI involves representing information in the problem as a diagram, which is known to mediate problem solution. Although results on the strategy knowledge assessment were not statistically significant (possibly due to low statistical power), low ability students' mean response $(0.83)$ to the item about organizing information from a word problem using a diagram was comparatively lower than that of average (1.29) and high ability (1.32) students. This finding suggests that the value of integrating metacognitive strategy knowledge as an instructional feature in SBI, particularly using schematic diagrams to represent information, may not have been realized in the short-term (10-day) intervention for low ability students. In contrast, this feature of the intervention may be one plausible explanation for high and average achieving SBI students' enhanced and sustained problem-solving performance. It must be noted that our problem solving measure was not as closely aligned with the intervention as those employed in previous research on SBI and may potentially be considered a transfer measure given that it included items from $8^{\text {th }}$ grade. As such, this test required students to reflect on the problem solving process and monitor their cognitive processes to promote transferable knowledge (e.g., Harris, Graham, \& Mason, 2006). In contrast, the performance of low achieving students in SBI was comparable to their peers in the control condition on the delayed posttest. This finding suggests that low achieving students in SBI did not benefit from metacognitive strategy knowledge training. It may be that low achieving students require more practice, time, and scaffolding to monitor and control their thought 
processes to positively influence learning as compared to students at other achievement levels. These findings suggest the need for future research to investigate the effectiveness of metacognitive strategy knowledge for students of diverse ability levels when used in isolation or in combination with SBI.

The present results offer at least two implications for theories of mathematical problem solving. First, consider the focus in SBI on multiple solution strategies. Prior work in special education has not encouraged the use of such an approach, particularly for low achieving students, because many special educators are skeptical of its benefits. One possible explanation for this skepticism among special educators is the inability of many low achieving students to meet the cognitive overload involved in learning multiple strategies (see Baxter, Woodward, Voorhies, \& Wong, 2002; Woodward, 2006; Woodward \& Montague, 2002). Although ability level did not mediate the effects of SBI in this study, visual inspection of the data suggested that, contrary to prior work in special education, the pretest to posttest progress of students in the low ability classrooms was comparable to the performance of low achieving students in the control condition $^{2}$. If exposure to multiple strategies did not impede the learning of low achieving students in the SBI condition, the cognitive overload of learning multiple strategies in SBI may not necessarily be a concern, for several reasons. First, we focused on a relatively small set of strategies (three) - only two of which were new for most students. Second, there were relatively obvious differences between strategies in terms of ease of application, in that some strategies were computationally easier to apply on some problems. Third, instruction explicitly focused on a comparison of strategies, including identification of which strategies were easier to implement on which problems (and why), consistent with the recommendations of prior research in this area (Rittle-Johnson \& Star, 2007; Star \& Rittle-Johnson, 2009). Interestingly, findings from the 
student metacognitive strategy knowledge assessment about the relative ease of each of the three strategies in solving ratio and proportion problems suggest that low ability students deemed cross multiplication to be easier $($ mean $=0.75, \mathrm{SD}=0.45)$ than the equivalent fractions $($ mean $=0.33$, $\mathrm{SD}=0.49)$ or unit rate strategies (mean $=0.50, \mathrm{SD}=0.52)$. This finding is not unexpected given that students were taught cross multiplication prior to the study. Had sufficient time been allocated for instruction on multiple solution strategies that are both understood and computationally easy to apply, low achievers (who may be sensitive to not only linguistic demands but also computational demands of word problem solving) might have experienced greater problem solving success. This possibility seems critical to explore in future research.

Second, the present findings point to the merits of strategy instruction using problem solving heuristics that are intermediate in generality. Prior work has questioned the usefulness of approaches that are overly superficial (such as keyword methods), as well as those that are too general (i.e., Pólya’s four-step model). Our approach linked a general four-step heuristic (FOPS) with the use of schematic diagrams, which emphasized the mathematical structure of specific types of problems. For a given word problem, the schematic diagram appeared to help students identify the underlying mathematical structure and interpret the problem situation, which was then used with the FOPS heuristic to mediate the problem's solution. Unlike the "draw a diagram” strategy in Polya’s heuristic that assumes "a student would know what pictures to draw when, and under what circumstances, and for which type of problems (Lesh \& Zawojewski, 2007, p. 768), the diagram strategy in SBI is more prescriptive in that the schematic diagrams are linked to specific types or classes of problems (e.g., ratio, proportion) to facilitate problem solving. At the same time, SBI does not rely on superficial cues and is not overly prescriptive like the key word approach to impede problem solving. 
The findings presented here must be interpreted with caution given that a potential limitation of the present study is the use of student as the unit of analysis. Because students are nested within classrooms, students' scores are not likely to be independent. As such, the use of this unit of analysis may violate a necessary condition of statistical tests used in the present analysis. However, our rationale of using the student as the unit of analysis is that the classroom variable is indirectly accounted for in our model, in that ability level and treatment group variables in essence define the classroom in our design. Future intervention research should ensure that conditions can be randomly assigned on a large-scale basis in which sufficient sample sizes can be secured to run hierarchical linear modeling or multilevel modeling.

Despite the above limitation, the results of the present study are particularly noteworthy given several factors that seemed to undermine the success of SBI instruction in this study. First, our observations of classroom instruction indicated that one of the control teachers in the high ability classroom (a very experienced teacher who only taught control classes) chose to deviate from the textbook presentation in ways that happened to align with our instructional intervention. In particular, he chose to present students with multiple solution strategies for solving ratio and proportion problems, rather than focus on the single strategy provided in the text (e.g., cross multiplication). Second, one of the intervention teachers in the low ability group experienced persistent classroom management difficulties that may have had a negative impact on student achievement and/or motivation. Third, implementation fidelity was, on the whole, lower than we had hoped. Despite these issues, all of which worked against the likelihood of success of the intervention, SBI was found to be effective. At the same time, in future research with teachers implementing this intervention (particularly in larger studies, over an extended period of time), it will be important to preemptively address these potentially undermining issues. 
A related issue that merits consideration as our investigation of SBI continues is whether the short professional development provided to treatment teachers (one day, followed by ongoing and optional technical assistance) is sufficient. Additional professional development may be necessary to improve treatment fidelity. More in-depth professional development might also help allay some teachers’ initial discomfort with the scripted nature of the SBI curriculum.

Also, increasing professional development would allow teachers and researchers to think more carefully about how SBI may need to be differentiated to meet the needs of students with differing ability levels, especially low achieving students who did not make adequate progress. One hypothesis for this finding is that the present intervention was time-based (with a fixed 10day length of instruction) rather than criterion-based (with length of instruction focusing more on students' mastery of content), which may not be optimal for meeting the needs of some low achieving students. Given the relatively limited time in the typical curriculum (and thus in SBI in this study) allocated to a critical topic such as ratio and proportion, it is possible that these students were not able to adequately integrate and internalize the information and strategies presented to impact the outcomes in this study. Therefore, it is crucial to consider examining instructional intensity for these low achieving students, who may need extended duration and intensive instruction that is perhaps even more explicit and systematic (e.g., teacher explanations and demonstrations, numerous opportunities to interact with the instructional materials and to think aloud, careful sequencing of problems) to learn the content (e.g., National Mathematics Panel Report, 2008). As such, our future research will investigate whether the addition of an ad hoc pull-out tutoring component for some low achieving students would help them catch up with their normally achieving peers. 
In conclusion, the focus on ratio and proportion problems in the present study extends into middle school and to students with diverse needs the prior work on word problem solving with students with disabilities or low achieving students in other mathematical domains from the elementary and middle school curriculum. The present findings suggest that students can benefit from instruction that emphasizes the underlying mathematical structure of word problems, an important feature of SBI. 


\section{References}

Ahl, V. A., Moore, C. F., \& Dixon, J. A. (1992). Development of intuitive and numerical proportional reasoning. Cognitive Development, 7, 81-108.

Bailey, R., Day, R., Frey, P., Howard, A.C., Hutchens, D.T., McClain, K., Moore-Harris, B., Ott, J.M., Pelfrey, R., Price, J., Vielhaber, K., \& Willard, T. (2004). Glencoe Mathematics: Applications and Concepts: Course 2. NY: The McGraw-Hill Companies, Inc.

Baker, S., Gersten, R., \& Lee, D. (2002). A synthesis of empirical research on teaching mathematics to low-achieving students. The Elementary School Journal, 103, 51-73.

Ball, D. L. (1993). With an eye on the mathematical horizon: Dilemmas of teaching elementary school mathematics. The Elementary School Journal, 93, 373-397.

Baxter, J., Woodward, J., Voorhies, J., \& Wong, J. (2002). We talk about it, but do they get it? Learning Disabilities: Research \& Practice, 17, 173-185.

Baxter, J., \& Woodward, J., \& Olson, D. (2001). Effects of reform-based mathematics instruction in five third grade classrooms. Elementary School Journal, 101, 529-548.

Behr, M., Harel, G., Post, T., \& Lesh, R. (1992). Rational number, ratio and proportion. In D. Grouws (Ed.), Handbook of Research on Mathematics Teaching and Learning (pp. 296333). NY: Macmillan Publishing.

Behr, M., Wachsmuth, I., Post T., \& Lesh R. (1984). Order and equivalence of rational numbers: A clinical teaching experiment. Journal for Research in Mathematics Education, 15(5), 323-341.

Ben-Zeev, T., \& Star, J. R. (2001). Spurious correlations in mathematical thinking. Cognition and Instruction, 19, 253-275. 
Briars, D. J., \& Larkin, J. H. (1984). An integrated model of skill in solving elementary problems. Cognition and Instruction, 1, 245-296.

Bright, G. W., Joyner, J. M., \& Wallis, C. (2003). Assessing proportional thinking. Mathematics Teaching the Middle School, 9, 166-172.

Boyer, T. W., Levine, S. C., \& Huttenlocher, J. (2008). Development of proportional reasoning: Where young children go wrong. Developmental Psychology, 44, 1478-1490.

Carpenter, T., Fennema, E., \& Romberg, T. (1993). Rational numbers: An integration of research. Hillsdale, NJ: Lawrence Erlbaum.

Chen, Z. (1999). Schema induction in children's analogical problem solving. Journal of Educational Psychology, 91, 703-715.

Cohen, D. \& Hill, H. (2001). Learning policy: When state education reform works. New Haven, CT: Yale University Press.

Coldberg, P. \& Bush, W. (2003). Using metacognitive skills to improve 3rd graders' math problem solving. Focus on Learning Problems in Mathematics, 5(10), 29-48.

CTB/McGraw-Hill. (1986). California Achievement Tests: Forms E and F. Technical Bulletin 2. Monterey, CA: Author.

CTB/McGraw-Hill. (2001). TerraNova. Monterey, CA: Author.

Cummins, D.D., Kintsch, W., Reusser, K., \& Weimer, R. (1988). The role of understanding in solving word problems. Cognitive Psychology, 20, 405-438.

De Corte, E., Verschaffel, L., \& De Win, L. (1985). Influence of rewording verbal problems on children's problem representations and solutions. Journal of Educational Psychology, 77, 460-470.

De Corte, E., Verschaffel, L., \& Masui, C. (2004). The CLIA-model: A framework for designing 
powerful leaming environments for thinking and problem solving. European Journal of Psychology of Education, 19, 365-384.

De Corte, E., Verschaffel, L., \& Op’t Eynde, P. O. (2000). Self-regulation: A characteristic and a goal of mathematics education. In M. Boekaerts, P. R. Pintrich \& M. Zeidner (Eds.), Handbook of self-regulation (pp. 687-726). San Diego: Academic Press.

Desoete, A., Roeyers, H., \& De Clercq, A. (2003). Can offlime metacognition enhance mathematical problem solving? Journal of Educational Psychology, 95, 188-200.

Fraivillig, J. L., Murphy, L. A., \& Fuson, K. (1999). Advancing children's mathematical thinking in everyday mathematics classrooms. Journal for Research in Mathematics Education, 30, 148-170.

Fuchs, L. S., Fuchs, D., Prentice, K., Burch, M., Hamlett, C. L., Owen, R., \& Schroeter, K. (2003). Enhancing third-grade students' mathematical problem solving with self-regulated learning strategies. Journal of Educational Psychology, 95, 306-315.

Fuchs, L. S., Seethaler, P. M., Powell, S. R., Fuchs, D., Hamlett, C. L., \& Fletcher, J. M. (2008). Effects of preventative tutoring on the mathematical problem solving of third-grade students with math and reading difficulties. Exceptional Children, 74, 155-173.

Fujmura, N. (2001). Facilitating children's proportional reasoning: A model of reasoning processes and effects of intervention on strategy change. Journal of Educational Psychology, 93, 589-603.

Fuson, K.C., \& Abrahamson, D. (2005). Understanding ratio and proportion as an example of the apprehending zone and conceptual-phase problem-solving models. In J. Campbell (Ed.), Handbook of mathematical cognition (pp. 213-234). New York: Psychology Press.

Fuson, K.C., Carroll, W.M., \& Drueck, J.V. (2000). Acheivement results for second and third 
graders using the Standards-based curriculum Everyday Mathematics. Journal for Research in Mathematics Education, 31, 277-295.

Fuson, K. C., \& Willis, G. B. (1989). Second graders' use of schematic drawings in solving addition and subtraction word problems. Journal of Educational Psychology, 81, 514-520.

Gentner, D., Loewenstein, J., \& Thompson. (2003). Learning and transfer: A general role for analogical encoding. Journal of Educational Psychology, 95(2), 393-405.

Gersten, R., Baker, S., \& Lloyd, J. W. (2000). Designing high-quality research in special education: Group experimental design. Journal of Special Education. 34, 2-18.

Gersten, R., Fuchs, L. S., Compton, D. Coyne, M., Greenwood, C., \& Innocenti, M. (2005). Quality indicators for group experimental and quasi-experimental research in special education. Exceptional Children, 71, 140-164.

Griffin, C. C. \& Jitendra, A. K. (2008). Word problem solving instruction in inclusive third grade mathematics classrooms. Journal of Educational Research, 102, 187-202.

Harris, K. R., Graham, S., \& Mason, L. H. (2006). Improving the writing, knowledge, and motivation of struggling young writers: Effects of self-regulated strategy development with and without peer support. American Educational Research Journal. 43, 295-340.

Hegarty, M., \& Kozhevnikov, M. (1999). Types of visual-spatial representations and mathematical problem solving. Journal of Educational Psychology, 91, 684-689.

Harel, G., Behr, M., Post, T., \& Lesh, R. (1992). The Blocks Task: Comparative analyses of the task with other proportion tasks and qualitative reasoning skills of seventh grade children in solving the task. Cognition and Instruction, 9(1), 45-96.

Huffred-Ackles, K., Fuson, K., \& Sherin Gamoran, M. (2004). Describing levels and components of a math-talk learning community. Journal for Research in Mathematics 
Education, 35(2), 81-116.

Janvier, C (1987). Problems of representation in the teaching and learning of mathematics. Hillsdale, NJ: Erlbaum.

Jitendra, A., DiPipi, C. M., \& Perron-Jones, N. (2002). An exploratory study of schema-based word problem solving instruction for middle school students with learning disabilities: An emphasis on conceptual and procedural understanding. The Journal of Special Education, 36, 23-38.

Jitendra, A. K., Griffin, C., Deatline-Buchman, A., \& Sczesniak, E. (2007). Mathematical word problem solving in third grade classrooms. Journal of Educational Research, 100, 283302.

Jitendra, A. K., Griffin, C., Haria, P., Leh, J., Adams, A., \& Kaduvetoor, A. (2007). A comparison of single and multiple strategy instruction on third grade students' mathematical problem solving. Journal of Educational Psychology, 99, 115-127.

Jitendra, A. K., Griffin, C., McGoey, K., Gardill, C, Bhat, P., \& Riley, T. (1998). Effects of mathematical word problem solving by students at risk or with mild disabilities. Journal of Educational Research, 91, 345-356.

Jitendra, A., \& Hoff, K. (1996). The effects of schema-based instruction on mathematical word problem solving performance of students with learning disabilities. Journal of Learning Disabilities, 29, 422-431.

Jitendra, A. K., Hoff, K., \& Beck, M. M. (1999). Teaching middle school students with learning disabilities to solve word problems using a schema-based approach. Remedial and Special Education, 20, 50-64. 
Jitendra, A. K., \& Xin, Y. P. (1997). Mathematical word problem solving instruction for students with disabilities and at risk: A research synthesis. Journal of Special Education, 30, 412-439.

Kalyuga, S., \& Sweller, J. (2004) Measuring knowledge to optimize cognitive load factors during instruction. Journal of Educational Psychology, 96, 558-568.

Kintsch, W., \& Greeno, J. G. (1985). Understanding and solving word arithmetic problems. Psychological Review, 92, 109-129.

Kramarski, B., Mevarech, Z. R., \& Arami, M. (2002). The effects of metacognitive instruction on solving mathematical tasks. Educational Studies in Mathematics, 49, 225-250.

Kramarski, B., \& Mizrachi, N. (2006). Online discussion and self-regulated learning: Effects of instructional methods on mathematical literacy. Journal of Educational Research, 99, 218230.

Lamon, S. J. (1993). Ratio and proportion: Connecting content and children’s thinking. Journal for Research in Mathematics Education, 24, 41-61.

Lamon, S. J. (1999). Teaching fractions and ratios for understanding: Essential content knowledge and instructional strategies for teachers. Mahwah, NJ: Erlbaum, 27, 170-193.

Lamon, S. J. (2002). Part-whole comparisons with unitizing. In B. Litwiller (Ed.), Making sense of fractions, ratios, and proportions (pp. 79-86). Reston, VA: National Council of Teachers of Mathematics.

Lamon, S. J. (2007). Rational numbers and proportional reasoning: Toward a theoretical framework for research. In F. K. Lester, Jr. (Ed.), Second handbook of research on mathematics teaching and learning (pp. 629-668). National Council of Teachers of Mathematics, Charlotte, NC: Information Age Publishing. 
Lampert, M. (1990). When the problem is not the question and the solution is not the answer: Mathematical knowing and teaching. American Educational Research Journal, 27, 29-63.

Lesh, R., \& Zawojewski, J. (2007). Problem solving and modeling. In F. K. Lester, Jr. (Ed.), Second handbook of research on mathematics teaching and learning (pp. 763-804). National Council of Teachers of Mathematics, Charlotte, NC: Information Age Publishing. Lesh, R., Post, T., \& Behr, M. (1988). Proportional Reasoning. In J. Hiebert \& M. Behr (Eds.) Number Concepts and Operations in the Middle Grades (pp. 93-118). Reston, VA: Lawrence Erlbaum \& National Council of Teachers of Mathematics.

Lester, F. K., \& Kehle, P. E. (2003). From problem solving to modeling: The evolution of thinking about research on complex mathematical activity. In R. Lesh \& H. Doerr, (Eds.), Beyond constructivism: Models and modeling perspectives on mathematics problem solving, learning, and teaching (pp. 501-518). Mahwah, NJ: Erlbaum.

Lester, F. K., Garofalo, J., \& Kroll, D.L. (1989). Self-confidence, interest, beliefs, and metacognition: Key influences on problem-solving behavior. In D. B. McLeaod \& V. M. Adams (Eds.), Affect and mathematical problem solving: A new perspective (pp. 75-88). New York: Springer-Verlag.

Lewis, A. B. (1989). Training students to represent arithmetic word problems. Journal of Educational Psychology, 8, 521-531.

Litwiller, B., \& Bright, G. (2002). Making sense of fractions, ratios, and proportions. Reston, VA: National Council of Teachers of Mathematics.

Lo, J., \& Watanabe, T. (1997). Developing ratio and proportion schemes: A story of a fifth grader. Journal for Research in Mathematics Education, 28, 216-236.

Lopez-Real, F. (2006). A new look at a Polya problem. Mathematics Teaching, 196, 12-15. 
Marshall, S. P. (1995). Schemas in problem solving. New York: Cambridge University Press.

Mayer, R. E. (1992). Thinking, problem solving cognition. San Francisco: Freeman.

Mayer, R.E. (1999). The promise of educational psychology Vol. I: Learning in the content areas. Upper Saddle River, NJ: Merrill Prentice Hall.

Mayer, R. E. (2004). Should there be a three-strike rule against pure discovery learning? The case for guided methods of instruction. American Psychologist, 59(1), 14-19.

National Council of Teachers of Mathematics (2000). Principles and Standards for School Mathematics. Reston, VA: Author.

National Mathematics Advisory Panel (2008). Foundations for Success: The Final Report of the National Mathematics Advisory Panel. Washington, DC.: U.S. Department of Education.

National Research Council (2001). Adding it up: Helping children learn mathematics. J. Kilpatrick, J. Swafford, and B. Findell (Eds.) Mathematics Learning Study Committee, Center for Education, Division of Behavioral and Social Sciences and Education. Washington, DC: National Academy Press.

Pintrich, P. (2002). The Role of metacognitive knowledge in learning, teaching, and assessing. Theory into Practice. 41, 219-225.

Pintrich, P., \& De Groot, E. V. (1990). Motivational and self-regulated learning components of classroom academic performance. Journal of Educational Psychology. 82,33-40.

Post, T. R., Behr, M. J., \& Lesh, R. (1988). Proportionality and the development of prealgebra understandings. In A. Coxford \& A. Shulte (Eds.), The ideas of algebra, K-12 (pp. 78-90). Reston, VA: National Council of Teachers of Mathematics.

Richland, L. E., Zur, O., \& Holyoak, K. J. (2007). Cognitive supports for analogies in the 
mathematics classroom. Science, 316, 1128-1129.

Riley, M. S., Greeno, J. G., \& Heller, J. I. (1983). Development of children's problem-solving ability in arithmetic. In H. P. Ginsburg (Ed.), The development of mathematical thinking (pp. 153-196). New York: Academic Press.

Rittle-Johnson, B, \& Star, J.R. (2007). Does comparing solution methods facilitate conceptual and procedural knowledge? An experimental study on learning to solve equations. Journal of Educational Psychology, 99, 561-574.

Roehler, L. R., \& Cantlon, D. J. (1997). Scaffolding: A powerful tool in social constructivist classrooms, In K. Hogan \& M. Pressley (Eds.), Scaffolding student learning: Instructional approaches and issues. Cambridge, MA: Brookline.

Schoenfeld, A. H. (1992). Learning to think mathematically: Problem solving, metacognition, and sense making in mathematics. In D. Grouws (Ed.), Handbook of research on mathematics teaching and learning (pp. 334-370). New York:McMillan.

Schoenfeld, A. H. (2002). Making mathematics work for all children: Issues of standards, testing, and equity. Educational Researcher, 31(1), 13-25.

Schunk, D.H. \& Zimmerman, B.J. (1994). Self-regulation in education: Retrospect and prospect. In D.H. Schunk \& B.J. Zimmerman (Eds.), Self-regulation of learning and performance: Issues and educational applications (pp. 305-314). Hillsdale, NJ: Erlbaum.

Silver, E. A., Ghousseini, H., Gosen, D., Charalambous, C., \& Strawhun, B. (2005). Moving from rhetoric to praxis: Issues faced by teachers in having students consider multiple solutions for problems in the mathematics classroom. Journal of Mathematical Behavior, 24, 287-301. 
Star, J.R., \& Rittle-Johnson, B. (2009). It pays to compare: An experimental study on computational estimation. Journal of Experimental Child Psychology, 102, 408-426.

Stigler, J. W., \& Hiebert, J. (1999). The teaching gap: Best ideas from the world's teachers for improving education in the classroom. New York: Free Press.

Swanson, H. L., Hoskyn, M., \& Lee, C. (1999). Interventions for students with learning disabilities: A meta-analysis of treatment outcomes. New York: Guilford.

Sweller, J., Chandler, P., Tierney, P., Cooper, M. (1990). Cognitive load as a factor in the structuring of technical material. Journal of Experimental Psychology: General, 119, 176192.

Stylianou, D. A., \& Silver, E. A. (2004). The role of visual representations in advanced mathematical problem solving: An examination of expert-novice similarities and differences. Mathematical Thinking and Learning, 6, 353-387.

Touvinen, J., \& Sweller, J. (1999). A comparison of cognitive load associated with discovery learning and worked examples. Journal of Educational Psychology, 91, 334-341.

Van de Walle, J.A. (2007). Elementary and Middle School Mathematics: Teaching Developmentally (6 ${ }^{\text {th }}$ edition). Boston: Pearson Education, Inc.

Van Dooren, W., De Bock, D., Hessels, A., Janssens, D., \& Verschaffel, L. (2005). Not everything is proportional: Effects of age and problem type on propensities for overgeneralization. Cognition \& Instruction, 23, 57-86, 30.

Verschaffel, L., De Corte, E., Lassure, S., Van Vaerenbergh, G., Bogaerts, H., \& Ratinckx, E. (1999). Learning to solve mathematical application problems: A design experiment with fifth graders. Mathematical Learning and Thinking, 1(3). 
Wearne, D., \& Kouba, V. L. (2000). Rational numbers. In E. A. Silver \& P. A. Kenney (Eds.), Results from the seventh mathematics assessment of the National Assessment of Educational Progress (pp. 163-191). Reston, VA: National Council of Teachers of Mathematics.

Whitehurst, G. J. (2003, April). The institute of education sciences: New wine, new bottles. Paper presented at the Annual Meeting of the American Educational Research Association, Chicago, IL.

Willis, G.B., \& Fuson, K.C. (1988). Teaching children to use schematic drawings to solve addition and subtraction word problems. Journal of Educational Psychology, 80, 191-201.

Woodward, J. (2006). Making reformed based mathematics work for academically low achieving middle school students. In Montague, M., \& Jitendra, A. K. (Eds.). Middle school students with mathematics difficulties (pp. 29-50). New York: Guildford.

Woodward, J., Baxter, J., \& Robinson, R. (1999). Rules and reasons: Decimal instruction for academically low achieving students. Learning Disabilities Research \& Practice, 14, 1524.

Woodward, J. \& Montague, M. (2002). Meeting the challenge of mathematics reform for students with LD. Journal of Special Education, 36, 89-101.

Xin, Y. P., \& Jitendra, A. K. (1999). The effects of instruction in solving mathematical word problems for students with learning problems: A meta-analysis. Journal of Special Education, 32, 207-225.

Xin, Y. P., Jitendra, A. K., \& Deatline-Buchman, A. (2005). Effects of mathematical word problem solving instruction on students with learning problems. Journal of Special Education, 39, 181-192. 
Zawaiza, T. B. W., \& Gerber, M. M. (1993). Effects of explicit instruction on community college students with learning disabilities. Learning Disabilities Quarterly, 16, 64-79.

Zimmerman, B. J. (1989). Models of self-regulated learning and academic achievement: Theory, research, and practice (pp.1-25). New York: Springer-Verlag.

Zimmerman, B. J. (2008). Investigating self-regulation and motivation: Historical background, methodological developments, and future prospects. American Educational Research Journal, 45, 166-183.

Zimmerman, B. J., \& Martinez-Pons, M (1990). Student differences in self-regulated learning: Relating grade, sex, and giftedness to self-efficacy and strategy use. Journal of Educational Psychology, 82, 51-59. 


\section{Footnotes}

${ }^{1}$ Separate one-factor ANCOVA's were conducted for each ability level, with the problem solving pretest serving as a covariate for the delayed posttest. Results for the high ability, $F(1,42)=$ 10.80, $p=.000$, and average ability levels, $F(1,69)=8.27, p=0.01$, indicated a statistically significant effect for group, favoring SBI. However, there was no statistically significant effect for the low ability level, $F(1,22)=0.43, p=0.52$.

${ }^{2} \mathrm{~A}$ repeated measures 2 group (SBI and control) x 2 time of testing (pretest and posttest) ANOVA for the low ability students indicated a statistically significant effect for time, $F(1,26)$ $=11.96, p<.002$; however, the main effect for group and the interaction of time by group effect were not statistically significant. 